\title{
Confirmatory factor analysis of self-evaluation spatial thinking skills (SESS) measurement model
}

\author{
Mushi Saumu Athumani a,1,*, Mohamad Sahari Nordin ${ }^{\text {a,2 }}$, Azlina Mustaffa a,3 \\ ${ }^{a}$ Kulliyah of Education, International Islamic University Malaysia, Malaysia \\ ${ }^{1}$ saumygift@gmail.com*; ${ }^{2}$ msahari@iium.edu.my; ${ }^{3}$ azlina910@yahoo.com \\ * corresponding author
}

\section{ARTICLE INFO}

Article history

Received 2020-03-10

Revised 2020-04-09

Accepted 2020-04-30

\section{Keywords}

Self Evaluation

Confirmatory Factor Analysis

Spatial skills

Spatial Reasoning

Spatial behavior

Undergraduates

\section{ABSTRACT}

Spatial skills are important interdisciplinary abilities for students in everyday practices and on their academic journey. Several measures of spatial thinking abilities have been developed for assessing spatial skills in the school context and students' spatial behavior in their everyday life. The commonly used one is the Self-Evaluation Spatial Skills (SESS), but it has not been validated. This study aimed to: (1) examine the extent to which the (Self Evaluation Spatial Skills (SESS) instrument developed by Wakabayashi constituted meaningful and interpretable three dimensions of spatial skills; (2) test the psychometric properties of the instrument in terms of reliability and convergent validity. Using slightly modified SESS of 19 items questionnaire, the data were collected from 351 undergraduates at International Islamic University Malaysia (IIUM). Confirmatory factor analysis indicated a fit model of three factors construct and confirmed the reliability and validity of the hypothesized measurement model. The results indicated the tested model as good for measuring students' spatial skills and spatial behavior in their local environment and in informing future research.

This is an open access article under the CC-BY-SA license.

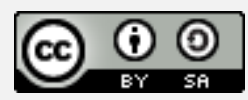

\section{Introduction}

Spatial thinking has been recognised by researchers as an important interdisciplinary ability relevant to many aspects of everyday life, workplace, and learning [1],[2]. In the modern society, students are not only required to master content knowledge for specific field of study but they are supposed to acquire multiple skills to help them supplement their competencies [3]. These skills among other significances, prepare them to become individual who can find answers on non-routine problems in any given context. Spatial thinking has varieties of definitions. For example, as ability to navigate, fix objects, understanding or estimating distance and measurement, reasoning and remembering the relationship among objects with respect to space identity, location, magnitude, and space-time [4]. Xiang and Liu regard it a mastering of the concepts of space, tools of representations and processes of reasoning. Spatial thinking permits individuals to comprehend relationships and structures in multiple ways and remember them using visual or any other form of mental representation like maps [4]. From Education perspective spatial thinking is the learners' mental ability to process information about objects in relation the environment or spaces [5]. This essential ability is acknowledged in education because it can be learned, same as other skills like language, mathematics and science. The Theory of Multiple Intelligences by Gardner [6] recognize spatial skills among the nine intelligences to provides means of learners to solve spatial problems Fig 1. He believes that this potential skill allows individuals to solve problems or fashion products that are of consequences in a particular cultural setting or community [7]. 


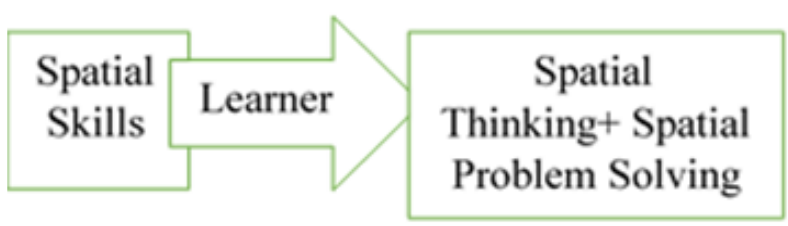

Fig. 1. Gardner theory of Spatial Intelligence

Several scales for spatial thinking have been proposed ranging from microscale for example figural (the immediate vicinity of the human body), environmental ( the immediate area in which a person lives and behaves), to geographic (the area that cannot usually be perceived from a single vantage point on earth) [4]. In this study the writer viewpoint of Spatial thinking is the ability for students to use the behavior of immediate area(environment)for structuring problems, seeking answers, and formulating possible solutions (decision making). The three constructs of Spatial thinking at local context that will be tested in this study are: First, Survey mapping (measure of students' awareness of orientation). Second, Route mapping (measure of students' ability to memorize landmarks upon environment navigation). Third, Spatial reasoning (measure student's capacity to think about objects in three dimensions and draw conclusion)

\subsection{Problem Statement}

The importance of spatial skills as prior experiences for students before they are getting into higher education has been long recognized [8]. Findings suggest that incorporating spatial skill activities into lessons had a positive impact on both the teachers' reflective practice and the students' learning skills [1]. While there have been many studies emphasizing on developing spatial thinking skills instruments [9],[10] few studies have been done to validate instruments for measuring spatial skills. In addition to the lack of validated spatial skills measurement ,these is a disagreement on the nature of instruments and the number of major components of spatial thinking skills to cater for multiples learners [9]. Therefore, there is a need to research more on the proper dimensions to measure the spatial thinking skills of students in some different contexts. This is one way of understanding where to improve in terms curriculum contents and teaching methods. The purpose of this study was to test the commonly used instrument known as Self-Evaluation Spatial Skills (SESS) for its validity in measuring Spatial thinking skills of undergraduate's students of IIUM.

\subsection{Study Objectives and Hypothesis}

The objectives of this study were to; i. Examining the extent at which the (Self Evaluation Spatial Skills (SESS) developed by Wakabayashi, consist of meaningful and interpretable 3 dimensions of spatial skills and (ii) to test the psychometric properties of questionnaire in terms of reliability and convergent validity. The study has two hypotheses; i.The three-factor SESS measure is adequate ii. The three factors SESS measure is psychometrically sound.

\section{Method}

Study population and sample: The study population involved the undergraduate's students of International Islamic University of Malaysia (IIUM), 351 students volunteered to participate by filling the questionnaire.

Data collection: The SESS questionnaire were administered to IIUM undergraduates who volunteered to participate in this study, the method was face to face whereby the researcher distributed the questionnaire on spot and waited for participants to fill and hand over to the researcher. Once the questionnaire has been collected, there follows data entry into SPSS version 22.

The Instrument: In collecting data, the slightly modified SESS questionnaire with 20 items was used to measure undergraduates spatial thinking skills and spatial reasoning in their everyday life. The original questionnaire were developed by [1] consists of 18 items . The first eight items named after survey mapping, the nature of items intended to measure awareness of orientation. The next six items 
measure route mapping, intended to measure one's ability to memorize landmarks in order to navigate an environment. The last six items named after spatial reasoning intended to measure student's everyday capacity to think about objects in three dimensions and draw conclusion using limited information about those objects. The researcher modified by replacing survey mapping with land mapping. This was done because most items explain more about land aspect. Another thing, the researcher added two items and a section for collecting demographic variables of the respondents such as gender and faculty.

Data analysis: Once the data has been key in to SPSS, A Confirmatory Factor Analysis(CFA) using the AMOS (Analysis of a Moment Structures) version 22, an added SPSS module. AMOS is a model fitting software applied to validate the hypothesized SESS measurement model. The confirmatory factor analysis was performed in order to verify the adequacy of the hypothesized measurement model. The adequacy of SESS model was assessed using the standards for a good fit CFA which includes; first the reasonableness of the parameter estimates and second, the consistency of the measurement model with the data. Relative Chi-square $\left(\left(\boldsymbol{x}^{2} / \boldsymbol{d} \boldsymbol{f}\right), \mathrm{CFI}(\mathrm{Comparative}\right.$ Fit Index $)$ and RMSEA(Root Mean square Error of Approximation ) was used as the fit indexes. The ranges recommended by Arbuckle \& Wothke [11] for a good model fit, it should be between $\mathbf{2}$ to 5 for $\mathrm{cmin} / \mathrm{df}$, CFI closer to 1 and for RMSEA value of $\mathbf{0 6}$ or less to show a reasonable error of estimation. The study tested the psychometric properties of the SESS measurement model by assessing the components of construct validity, i.e convergent validity. Composite reliability (CR) was used to measure the sub-construct's internal consistent.

\section{Results and Discussion}

This section explains the results of the study with respect to the previous stated objectives i.e. to examine the adequacy of the SESS in measuring spatial skills and to test the psychometric properties of questionnaire in terms of reliability and convergent validity. Two hypotheses were used to arrive to the study purpose: i. The 3-factor SESS measure is adequate ii. The three factors SESS measure is psychometrically sound. Table 1 . displays the descriptive statistics of the items included in the confirmatory analysis, the value of each Composite Reliability (CR), which is internal consistency index of the responses to the related items was high, the values exceeds the critical cut-score of .7 for reliable measure.

Table 1. Self-Evaluation Spatial Skills(SESS) dimensions and Items Statistics

\begin{tabular}{|c|c|c|c|c|c|c|c|}
\hline Code & Dimensions/sub-construct & Mean & $\begin{array}{c}\text { Std. } \\
\text { Deviation }\end{array}$ & Loadings & AVE & $\mathbf{C R}$ & Alpha \\
\hline & Route Mapping & & & .66 & .517 & .777 & .838 \\
\hline RM1 & $\begin{array}{l}\text { I become confused as to cardinal } \\
\text { directions, when I am in an unfamiliar } \\
\text { place }\end{array}$ & 3.75 & 1.298 & & & & \\
\hline RM2 & $\begin{array}{l}\text { When I get route information, I cannot } \\
\text { make use of cardinal directions. }\end{array}$ & 3.98 & 1.140 & .78 & & & \\
\hline RM3 & $\begin{array}{l}\text { It is difficult to understand the line of } \\
\text { the train in cardinal directions }\end{array}$ & 3.79 & 1.256 & .80 & & & \\
\hline RM4 & $\begin{array}{l}\text { I can make out which direction my room } \\
\text { in a hotel faces }\end{array}$ & 3.61 & 1.239 & .70 & & & \\
\hline RM5 & $\begin{array}{l}\text { I can easily find the place where I am on } \\
\text { a map. }\end{array}$ & 3.83 & 1.188 & .66 & & & \\
\hline SR1 & $\begin{array}{l}\text { Spatial Reasoning in Everyday life } \\
\text { I can easily recreate an origami piece } \\
\text { after watching someone else make it. }\end{array}$ & 3.88 & 1.158 & .61 & .599 & .913 & .835 \\
\hline SR2 & $\begin{array}{c}\text { I can pack a bag and a suitcase with } \\
\text { baggage well }\end{array}$ & 3.84 & 1.113 & .67 & & & \\
\hline SR3 & $\begin{array}{l}\text { I can easily assemble a model and } \\
\text { electrical appliance according to manual }\end{array}$ & 3.85 & 1.185 & .77 & & & \\
\hline SR4 & $\begin{array}{l}\text { I can easily visualize my room with a } \\
\text { different furniture arrangement }\end{array}$ & 3.85 & 1.189 & .74 & & & \\
\hline SR5 & I am good at playing ball games & 3.85 & 1.203 & .75 & & & \\
\hline LM1 & $\begin{array}{c}\text { Land Mapping } \\
\text { I can use landmarks in wayfinding }\end{array}$ & 3.71 & 1.301 & .63 & .539 & .842 & .920 \\
\hline LM2 & $\begin{array}{l}\text { I can remember landmarks found in the } \\
\text { area where I have often been. }\end{array}$ & 3.68 & 1.370 & .66 & & & \\
\hline
\end{tabular}




\begin{tabular}{|c|c|c|c|c|c|c|c|}
\hline Code & Dimensions/sub-construct & Mean & $\begin{array}{c}\text { Std. } \\
\text { Deviation }\end{array}$ & Loadings & AVE & $\mathbf{C R}$ & Alpha \\
\hline LM3 & $\begin{array}{c}\text { I can remember the different aspects of } \\
\text { sceneries. }\end{array}$ & 3.85 & 1.295 & .64 & & & \\
\hline LM4 & $\begin{array}{l}\text { I can grasp distance expressed in meters } \\
\text { or kilometre units }\end{array}$ & 3.64 & 1.389 & .78 & & & \\
\hline LM5 & $\begin{array}{l}\text { I can relate the actual land patterns and } \\
\text { the map patterns of land features }\end{array}$ & 3.73 & 1.277 & .78 & & & \\
\hline LM6 & $\begin{array}{c}\text { I cannot identify the landmark I am } \\
\text { looking using a map }\end{array}$ & 3.67 & 1.219 & .79 & & & \\
\hline LM7 & $\begin{array}{l}\text { I can clearly lead someone the correct } \\
\text { land mark using a sketch map }\end{array}$ & 3.68 & 1.266 & .78 & & & \\
\hline LM8 & $\begin{array}{l}\text { I often forget which land direction I } \\
\text { turned }\end{array}$ & 3.65 & 1.273 & .74 & & & \\
\hline LM9 & $\begin{array}{l}\text { I do not verify landmarks in a turn of the } \\
\text { route. }\end{array}$ & 3.81 & 1.255 & .78 & & & \\
\hline LM10 & $\begin{array}{l}\text { On the apparent similar road, I can } \\
\text { distinguish a difference immediately }\end{array}$ & 3.71 & 1.384 & .75 & & & \\
\hline
\end{tabular}

1) Adequacy of 3-factors SESS measurement model

To examine the adequacy of the modified 3-factors SESS instrument, CFA was applied. The result of the CFA shows that, the hypothesized 3-factors SESS model was adequate ( see Fig.2). The SESS measurement model fitted the variance-covariance matric; $\left(\boldsymbol{x}^{2} / \boldsymbol{d} \boldsymbol{f}\right)=\mathbf{2 . 2 0 2}$; $\mathrm{CFI}=. \mathbf{9 4 7}$; RMSEA=.059. All parameter estimates were statistically significant. The standardized factors' loadings were seen as far more than 0.5,ranged between 0.61-0.80, this indicates that the factor loadings are all acceptable with the sample size of 315 far more than 255 as minimum proposed size by [12]. Hence the scale items were valid.

\section{2) Psychometric Properties of SESS measurement model}

The results show evidence to support the psychometric properties of the Self Evaluation Spatial Skills instrument in terms of its composite reliability (CR)and convergent validity. In (Table 1) the reliability of the scale was assessed based on the CR indicator, the result indicated to have the acceptable levels based on the fact that , 0.5 or more is considered good indicator of reliability [13]. The value of Average Amount of Variation(AVE)which explains the convergent validity of measurement constructs was found to be larger than the recommended value of $\mathbf{. 5 0}$ according to [14]. Therefore, each factor indicated sufficient property of convergent validity see Table 2 .

Table 2. Summary of CFA Hypothesis Testing Results

\begin{tabular}{cc}
\hline Hypothesis & Results \\
\hline H1 The Three=factor SESS measure is adequate & Supported \\
H2 The three factors SESS measure is psychometrically sound & Supported \\
\hline
\end{tabular}

This study aimed first; to examine the extent at which the (Self Evaluation Spatial Skills (SESS) developed by Wakabayashi, consist of meaningful and interpretable 3 dimensions of spatial skills and second; to test the psychometric properties of instrument in terms of reliability and convergent validity. The results indicated the adequacy of the three-factors SESS measurement model in measuring Spatial thinking skills of students and spatial behavior in their everyday life. This confirmed by $\left(\boldsymbol{x}^{2} / \boldsymbol{d} \boldsymbol{f}\right)=2.202 ; \mathrm{CFI}=.947 ; \mathrm{RMSEA}=.059$ As for the reliability and validity ,the result supported the null hypothesis that SESS measurement model is valid. The CR values of the construct all supported the reliability indexes ranges from .777,.913 to .842 and the AVE $(.517, .599$ and .539$)$ supported the Convergent validity of the constructs. 


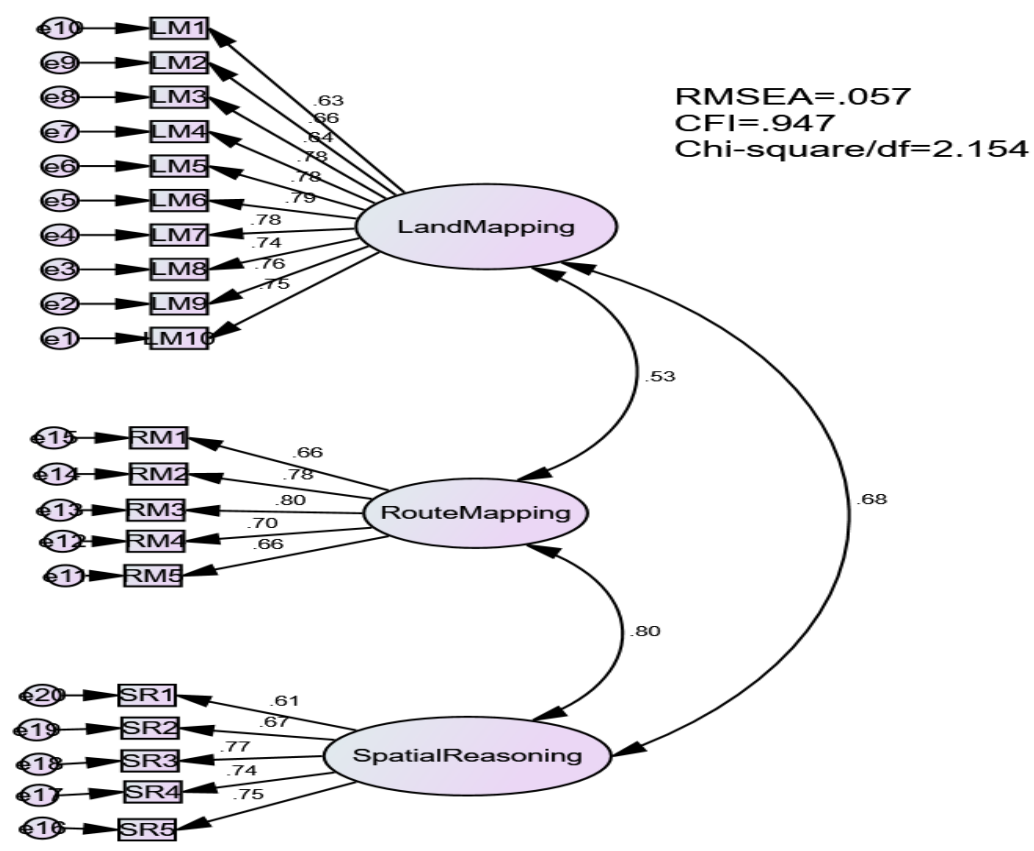

Fig. 2. Three-Factors SESS Measure

Therefore, based on the results see Fig. 2, the SESS instrument for Spatial thinking skills used in the study is recommendable practically useful in assessing students' ability in framing the association between daily learning activities and their existing physical environment. This present study supported previous work on the importance of assessing spatial thinking skills to students and therefore the instrument can help to serve that purpose. For example [9] on their study commend that, in order for students to conceptualize space, understand representations, and reason spatially, they must possess the appropriate spatial skills. Similarly, as noted recently by [15],[16] extracurricular activities appear to develop spatial skills throughout students' lives therefore they suggest a systematic informal training opportunity for students. This would facilitate their spatial reasoning abilities and hence improve their thinking skills in general.

\section{Conclusion}

Spatial thinking skills are important interdisciplinary abilities for students in everyday practices and on their learning. To have the appropriate measure of spatial thinking skills which cater for various groups of learners is essential. Similarly, understanding how learners can develop and apply spatial thinking skills in their specific field of learning can give light to curricular and educationist to plan ahead [17],[18]. This particular study indicated that, behavioral activities in which students engage, justified by SESS instrument can be used to determine their spatial thinking skills. Therefore, this study recommends future research to firstly, find out the nature of the relationship between the determinants of spatial thinking skills in different or with other external factors. Finally, other context and methodology can be used to research further on the determinants of spatial thinking skills among learners

\section{References}

[1] Y. Wakabayashi, "Measurement of Spatial Thinking Abilities and the Factors Affecting them," Tokyo, 2015, available at: Google Scholar.

[2] C. Charcharos, M. Kokla, and E. Tomai, "Investigating the Influence of Spatial Thinking in Problem Solving," Athens, 2016, available at: Google Scholar.

[3] J. Otero and M. Torres, "Spatial Data Infrustructures and Geography learning," Eur. J. Geogr., vol. 8, no. 3, pp. 19-29, 2017, available at: Google Scholar. 
[4] R. Golledge, M. Marsh, and S. Battersby, "A conceptual framework for facilitating spatial thinking," Ann. Assoc. Am. Geogr., vol. 98, no. 2, pp. 285-308, 2016, doi: 10.1080/00045600701851093.

[5] B. N. Verdine, R. M. Golinkoff, K. Hirsh-Pasek, and N. S. Newcombe, "Spatial Skills, Their Development, and Their Links To Mathematics," Monogr. Soc. Res. Child Dev., vol. 82, no. 1, pp. 7-30, 2017, doi: 10.1111/mono.12280.

[6] H. Gardner, Frames of mind: The theory of multiple intelligences. New York: Basic Books, 1983, available at: Google Books.

[7] A. Jordan, O. Carlile, and A. Stack, Approaches to Learning:A Guide for Teachers. N ew York: McGrawHill, 2009, available at: Google Books.

[8] A. M. Dolan, F. Waldron, S. Pike, and R. Greenwood, "Student teachers' reflections on prior experiences," Int. Res. Geogr. Environ. Educ., vol. 23, no. 4, pp. 314-330, 2014, doi: 10.1080/10382046.2014.946324.

[9] J. Lee and R. Bednarz, "Components of Spatial Thinking: Evidence from a Spatial Thinking Ability Test," J. Geog., vol. 111, no. 1, pp. 15-26, 2012, doi: 10.1080/00221341.2011.583262.

[10] B. Tomaszewski, A. Vodacek, R. Parody, and N. Holt, "Spatial Thinking Ability Assessment in Rwandan Secondary Schools: Baseline Results," J. Geog., vol. 114, no. 2, pp. 39-48, 2015, doi: 10.1080/00221341.2014.918165.

[11] J. Arbuckle and W. Wothke, AMOS for user's reference guide. Chicago: Smallwaters Corporation., 1999, available at: Google Scholar.

[12] J. Heir, W. Black, W. Babin, and R. Anderson, Multivariate data analysis, 6th ed. Uppersaddle River: Pearson Prentice Hall., 2006, available at: Google Scholar.

[13] A. Segars, "Assessing the unidimensionality of measurement:A paradigm and illustration within the context of information systems research.," Omega Int. J. Manag. Sci., vol. 25, no. 1, pp. 102-121, 1997, doi: 10.1016/S0305-0483(96)00051-5.

[14] C. Fornell and D. Lacker, "Evaluating structural equation models with unobservable variables and measurement error.," J. Mark. Res., vol. 18, no. 1, pp. 39-50, 1981, doi: 10.1177/002224378101800104.

[15] A. Gold et al., "Spatial skills in undergraduate students-Influence of gender, motivation, academic training, and childhood play," Geosphere, vol. 14, no. 2, pp. 668-683, 2018, doi: 10.1130/GES01494.1/4101636.

[16] B. Rittle-Johnson, E. L. Zippert, and K. L. Boice, "The roles of patterning and spatial skills in early mathematics development," Early Child. Res. Q., 2018, doi: 10.1016/j.ecresq.2018.03.006.

[17] M. Kim and R. Bednarz, "Development of critical spatial thinking through GIS," J. Geogr. High. Educ., vol. 37, no. 3, pp. 350-366, 2013, doi: 10.1080/03098265.2013.769091.

[18] X.Xiang and Y. Liu, "Understanding 'change' through spatial thinking using Google Earth in secondary geography”, J. Comp. Assist. Learn.,vol 33.no.1,pp. 65-78,2017, doi: 10.1111/jcal.12166. 